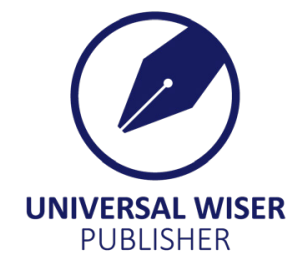

\title{
A Framework for Knowledge-Based Enterprise Financial Support in Iran
}

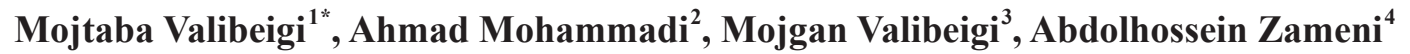 \\ ${ }^{1}$ Buein Zahra Technical University, Qazvin, Iran \\ ${ }^{2}$ Buein Zahra Technical University, Buein Zahra, Qazvin, Iran \\ ${ }^{3}$ Financial Expert of Mellat Bank, Iran \\ ${ }^{4}$ Graduate School of Business (GSB), SEGi University, Malaysia \\ E-mail: m.valibeigi@bzte.ac.ir
}

\begin{abstract}
In line with other Iranian protection laws for reducing unemployment and increasing the economic growth, knowledge-based enterprises' protection law faces to serious challenges that causes this law will not reach to its aim. The purpose of the study is to present a framework for financial support of Iranian knowledge-based enterprises based on British Investment Bank. This bank is a conjugation of intergovernmental and financial banking. This type of banking is not a competitor to other financial banks. The main tendency of such a bank is to support small and medium-sized knowledge-based enterprises which are in the early stages of their growth and are not attractive enough for investors. In a supportive environment with the right framework for funding, knowledge-based enterprises can both thrive and grow, and stimulate employment and economic growth.
\end{abstract}

Keywords: Iranian knowledge-based found, British investment bank, knowledge economy, knowledge-based enterprises, knowledge-based funding

\section{Introduction}

Following the long-term comprehensive national plan for development of Iran, a roadmap known as Vision 1404 (or Vision 2025 for the Gregorian calendar), Iranians aim to shift from reliance on a natural resource extraction oriented economy to a knowledge-based economy. With a decade remaining to reach the 20-year horizon, the construction of the main infrastructure necessary for the full deployment of science-based enterprises is under way, and the value-added of the knowledge-based companies constitutes a small fraction of the country's GDP ${ }^{[1]}$. According to Iran's 20-year vision plan(1404 A.H.S (Anno Hegirae Solaris)), Iranian knowledge-based enterprises are not acceptable qualitatively and quantitatively. One of the most important prerequisites for achieving the goal of Vision 1404 is development of New Technology-Based Firms (NTBFs) in Iran. These enterprises are the most influential players in the national system of innovation. Their influence is due to their ability to create high-skill job opportunities, slow the processes of brain drain, and contribute to economic growth. One of the important tasks of these enterprises is the diffusion of technology from research laboratories to the production sectors of the economy ${ }^{[1-3]}$. Some important challenges against of these kind of enterprises include unbalance governmental protection policies, conceptual challenge in treatment to knowledge-based enterprises, internal market stagnation and economic problems ${ }^{[4-7]}$.

It is important to point out that the aims of the Law of Supporting the Knowledge based Companies and Commercializing Innovations and Inventions (SKBECII), enacted in Iran (2010), are to form private knowledgebased enterprises that could create synergy between science and wealth, develop a knowledge-based economy, expand applications of inventions, and commercialize the results of R\&D in high-technology industries ${ }^{[1]}$. But most researches have shown that the most important challenge is related to financial factors and how financial support. Accordingly, this research deals with the issues of corporate financial support and appropriate financial support. Although the government's economic hypotheses seem to have lost their function, but in addition to overseeing and supporting private investments; Governors must create a favorable environment for the growth of knowledge-based enterprises, especially in related to small and medium-sized industries (SMEs). This is especially true in the case of Iran, where the government has a tremendous impact on economic activity due to its $85 \%$ share. According to the above explanations, the support manner should motivate and give sufficient facilities to the enterprises, although it should prevent their high reliance on the 
government.

The government's economic experience shows that insisting on the government's role in the development process of this type of enterprise will lead to large subsidies to certain groups, waste of time, and reduced productivity. On the other hand, these enterprises are not very attractive to banks and shareholders due to the new foundation and high investment risk. Therefore, they have many problems in financing. Therefore, this study presents a framework for governmental investment bank whose headlines are controlled by Majlis resolutions, so its implementation is not related to political barriers, and therefore the plan is to support investment in knowledge-based enterprises. The framework of present study consists of 3 main sections. In the first part, a brief description of the logic of public investment banks and financing funds 0is given, as well as a definition of knowledge-based enterprises appropriately for Iran. Then how to improve the financial efficiency of knowledge-based enterprises is investigated. In third section, operational issues related to such an investment fund is presented and finally, the topics, will be summarized and concluded.

\section{Literature review}

There are decisive evidences about the relationship of investment high levels with high growth and low unemployment ${ }^{[8,9]}$, however there is no definitive answer to this question that what is the optimum level of investment. There is a general agreement that increasing investment is an important parameter for the economy stable development and encouraging investment and exports are among the four main goals of development ${ }^{[10-12]}$. The growth of investment rises the level of collective-consumption, which increases the growth and demand for labor, consequently ${ }^{[13,14]}$. Broadening the definition domain of the knowledge-based enterprises based on the current situations of Iran, makes the financial supports of these enterprises more logical and with lower risk in addition to vast responding to their demands ${ }^{[15-17]}$. Accordingly, in line with FAKHARI ${ }^{[6]}$, the study has considered a broad definition of knowledge-based enterprises as the criterion:

The knowledge-based enterprises in Iran, mainly are some organizations (mostly small and medium) in private sector (structural class) which generated and managed by experts (resource class) to commercialize the innovations and inventions, making the researches applicable (process class) and localizing the technologies (production class). In these enterprises, the research and development is the main core of the activities (process class). The competitive advantage of these enterprises, is the technical knowledge and scientific abilities from the knowledge and innovation in various levels (market class). These enterprises have grown in a changing and knowledge-based environment (Growth model class) and have the long-term profitability (market class).

Governments play various roles in financial and nonfinancial supports of knowledge-based enterprises. In some cases, the government, invests in knowledge-based enterprises directly via the investment fund founding or facility granting to the knowledge-based enterprises. But the main role of the government is indirect ${ }^{[1,18,19]}$. The main duty of the government is to improve the business environment and create a suitable platform for innovation through economic and legal infrastructure or to help making a network of investors. Incentive policies about the innovation development in various countries, has moved from the direct approach to indirect one. In this condition, the government enhances the market mechanisms instead of its direct facing to the small and diverse knowledge-based enterprises. The reality is that huge knowledgebased enterprises have grown via the diverse tools of the nongovernmental financial supply instead of governmental facilities and loans. The most important role of the governments is that to make an appropriate environment for the private financial organizations such as Venture Capital (VC) funds or proper law codification for crowdfunding activities. These days, investment banks are professional advisors, helping and strengthening financial resources for their customers. When investment is low, the Public Investment Bank Foundation is a way to control demand and finance constraints. The Investment Bank links a set of small public funds in private markets to justifiable investment projects.

\section{The idea of improving the financial efficiency of knowledge-based enterprises}

The Iran's state banks are, faced to failure in financing for these enterprises; because they are not able to select the beneficially plans truly, in addition, they do not have a transparent lending method and instead, they are involved in political interaction. In this manner, the need for investment banks, known as financing funds in Iran, becomes apparent. A financing fund is a financial organization that helps people, enterprises and governments to obtain capital via the commitment acceptance or employer representation in issuance of securities. The financing enterprises also can attend the other financial services such as consultation on mergers and acquisitions, marketing, published financial instruments with fixed income and etc. these enterprises act in capital market mainly. The collected capital is given to the enterprises and projects via a wide range securities' distribution and investment funds. Upon to paragraph 18, Article 1 of the Law 
on the Securities Market of the Islamic Republic of Iran: financing enterprise is an enterprise that works as a mediator between the securities distributor and the investors. It can do some works such as brokerage, trading, marketing, consulting, acceptance commitment and the other similar works by the license obtaining from the Securities and Exchange Organization. Financing funds can also act as an intermediary between the government and enterprises that need financial support, and investors who have money and want to save it on securities purchasing. Investment bank existence logic relies on profitability lack of investment increasing.

Limitations for the investment in knowledge-based enterprises, unfortunately, originated from a dual nature which comes from both demand and supply-side parameters. The lack of stable policies in country industrial development for the small economic enterprises' protection, in addition to problems such as great oil revenues and disregarding of the foreign exchange earnings of small enterprises; along with lack of an organization which be the responsible to small economic enterprises have caused that the small economic enterprises could not develop in Iran. From the financial viewpoint, the small and medium knowledge-based enterprises have lots of problems such as the lack of recognition and awareness of banks to technological literature and functional ideas, lack of capital, disability in new financial devices introducing, raw material providing problem and products purchasing ${ }^{[2-22]}$. So, the amount of loan will not be important if a work does not happen for the demand stimulation in financial investment in knowledge-based enterprises. Due to market failure and lack of the enough demand, the government involving in knowledge-based enterprises in Iran comes up and the government plays the investor and final consumer role. For example, the British government has approved the National Loan Scheme Guarantee to strengthen the financing for the small and medium size enterprises. This governmental guarantee, contained to 20 thousand million dollars from the SME loans. The investment costs in SME was decreased via that work ${ }^{[23]}$. Therefore, the plan was more successful than the banks that developed small and medium-sized enterprises. At the same time, investment in knowledge-based enterprises is affected by financial crisis. Lack of confidence in the future performance about the investments, balances the demand for financial investment, meaningfully ${ }^{[23]}$. In 1931, the Macmillan Commission identified the 'Macmillan Gap' as the funding gap facing enterprises which become large enough to attract institutional investors ${ }^{[23-25]}$. In this gap, informational asymmetries are large while the administrative scale economies are small; both of these factors force banks to expect higher rates of interest. As a result, if a same loan given to all enterprises, many of interested SMEs will face to the stiff credit costs, which they cannot conform themselves to the higher rates of return investment. Also it limits the knowledge-based enterprises to reach the medium commercial investment markets, even the SMEs will face to debts payment and short time limitations on liquidity. This, over-compacts the GPD and employment ${ }^{[23]}$. Due to that, a mechanism should be designed by the government in pseudo-state economy, which can contain the supplyside in addition to demand parameter stimulation. Upon to Nordic Investment Bank and British investment bank samples that relies to this hypothesis, this kind of bank can decrease both the supply limitations and demand for the financial investment, without the oil revenues, put in danger. Public investment banks experience shows that this work is possible but it needs a careful thought about the organization designing of this kind of banks.

\section{Operational issues, related to investment funds' generation}

There are some public investment banks around the world such as Nordic Investment Bank, European Investment Bank, the Japanese Development Bank, Emerging Ontario Bank and technology fund of Cotton wood and can be the guide for the investment bank foundation in Iran and its localization according to the Iran conditions. Considering the abovementioned investment funds, the concentration of this part will put on British Investment Bank (BIB) suggestion framework, in present study.

British Investment Bank (BIB) belongs to United Kingdom (UK). Right of selection for the suitability determination of a financing project is the center point of success in this bank. In strategic level, BIB is loyal to commercial banking principles free of political influence, however, it works under a dual-layer instruction which is set up by House of Commons of the United Kingdom members. A conjugation of public supervision and commercial independence can be observed in BIB. This bank can be supervised by public control on capital in addition to its commercial independence for the proper decision making for the investment in presented projects. The first step of this kind of bank designing in Iran must be the high financial transparency and mandatory. This bank should give the financial facilities to the small and medium scale knowledge-based enterprises at the market entry stage. It should not be the rival for the private financial suppliers and prevents the knowledge-based enterprises' dependence. The investment banks should assume that they are the responsible for those projects which cannot provide their funds via the commercial banks.

As it said previously, accessing to the financial resources for the SMEs is difficult, especially when they are at beginning stage of their development ${ }^{[23]}$. Due to that, the first duty of this bank is to decrease the Knowledge-based 
enterprise's failure at their beginning in market.

Most of the present problems of the state and private banks in Iran is due to their non-compliance with international standards and also, the International Financial Reporting Standards (IFRS) doesn't be applied in most of the Iranian banks, caused the lack of transparency in Iranian banks, consequently. State banks face to this problem that if they report by new standards, they have to save for toxic assets and deferred demands. Upon to this, the profits could not be presented in paper form (provide facial financial statements), divide the profits in general assembly and increase their capital subsequently. Mellat Bank, for example, recorded its annual profit in its initial financial forms, but when it compiled the financial statement with standards, it could not divide the profit among the shareholders; Tejarat Bank had also the same situation. Saderat Bank was a unique example; because it had profit in initial financial statement, but when the Board of Directors changed, and new financial statements was reported, the billion Tomans (Iranian Rial or Toman is the official currency of Iran. At the time of research, Toman exchange rate to the dollar was $1 \$$ equals to 3280 Toman) financial loss was divided at the general assembly instead of the profit. the Iranian Knowledge-based Found (IKBF) should adhere to the standards from the foundation stage. Transparency will be more in consequence of the new report investment applying.

Such an instruction, can be an index for the relevant monitoring on success amount assessment of the bank by the Islamic Consultative Assembly (Parliament). The Central Bank, similar to BIB framework, should present an operative report about the Iranian Knowledge-based Found (IKBF) quota in country economy after its performing to needed regulations and modifications be done if it is necessary. While, the Iran's economy, nowadays faces to huge unemployment challenge and the GPD gap, the risk of crowding out, however, can be decreased via this procedure. Crowding out can weaken the economy competitiveness when it closes to production possibility frontier ${ }^{[25]}$. Ministry of Economic Affairs and Finance Studies show that upon to "the state of the country's labor market and its vision on the horizon of 1404" report ${ }^{[26]}$, according to the calculation of the 10-year growth rate, the country active population will be reached to 26.6 million persons from 24 million people at the beginning of period. Upon to Islamic Consultative Assembly research center prediction ${ }^{[27]}$, the unemployment rate in Iran at the end of decade 90 (2020) will reach to 18.9 and $21.2 \%$ in an optimistic scenario (economy growth rate equal to $5 \%$ ) and in a pessimistic scenario (economy growth rate equal to $1 \%$ ) respectively. It is obvious, so, if the joblessness rate less than $10 \%$ is the goal, it will need the economy growth rate more than $5 \%$.

IKBF, same as the public investment banks, should provide its lending operation via the long-term bonds' issuing to private investors. This bank can increase this loan gradually, using the implicit guarantee of government ownership. High credit and long-term bond due date of the IKBF, makes this fund attractive, for those group of organizations and people who want the investment safety with low risk and high benefits such as Country Pension Fund (CPF).

The IKBF loans are managed by the colleague banks, because it is not expected that the IKBF can develop a network of local branches. In other word, IKBF, can give the facilities and sell bonds via the co-worker banks, especially the Iranian private banks. So that the IKBF gives the loan via these banks to the right applicant, if the knowledge-based enterprises' eligibility conenterpriseed. IKBF, same as the NIB and BIB, to encourage private participants for the investment, undertakes $50 \%$ of financial supply. This procedure can encourage the personal investors for the investment, if it comes along with proper and acceptable quality for the financial aid giving. In the country, the personal investors often will be encouraging to invest in IKBF projects due to their high quality, lack of formalities and guaranteed profit. Generally, in this kind of fund, the government should supply the initial capital stock. The needed capital for the beginning can be same as the BIB investment, equal to $480 \mathrm{M} £$. This can be provided from the innovation and prosperity fund budget, which is about one billion dollars, the National Development Fund or the bonds sale to the national bank of Iran. The fundamentals and nature of this fund, the government has to provide the fund via the bonds facilities. Since, the IKBF, produces the returns on its investments, it can pay some of its profit for dividend to the government and the bonds will be depreciated due to that.

At the first step, the IKBF shows its loyalty to the long-term plan. This step is begun with internal consulting services, contain the recognition, providing and evaluation of eligible projects. Therefore, it can be assured that a line of IKBF loan applicants exists. IKBF, due to that, presents a message to its customers that there is a national important investment which is committed to sponsoring its relevant department (small and medium knowledge-based enterprises); therefore, a collection of approved projects, encourages the society for the investment. In relation with the commercial considerations, the consulting services can be in a form that the SMEs give the finance as their needs to provide a portion of supply chain under the government protection.

The IKBF lending, relates to the government long-term commitment against the market failure parameters such as the protection of privatization law. The government must increase the competitiveness in national economy and the economic enterprises' efficiency while it reduces its enterprises, based on the main principles of the article 44 general policies ${ }^{[2-31]}$. 
The obvious between the lending process and the government policies can affect the fund independence and put its market credit in danger. The balance making between the bank independence and political strategies is so difficult. IKBF can be an evidence of the government commitment to this plan and financial transparency. Due to aforementioned contents, the economic balance making, thus, is stated as one of the main policies in Iran's development plans. Therefore, the government should confront with those parameters which cause the market failure. Upon to Wigstrom ${ }^{[23]}$ and [25] the IKBF governmental possession is an implicit encouragement for the constant parliament strategies about the IKBF. Any changes in policies can weak the bank operation and increase the government implicit guaranteed value on IKBF loans. Without putting the bank independence in danger, the IKBF bank operation can show the government implicit commitment to support small and medium knowledge-based enterprises really. In consequence of the investment level increasing in economy, the IKBF rises the total cost level which improves the tax base and reduces the unemployment, subsequently. As the national income increases, each originated budget deficit, reduces accordingly, as a portion of GPD, although this is a short-term goal. Making a political strategy is not difficult, the political instance, indeed, should be conformed and simultaneous to the economic sample, where the political structure of the government accepts the IKBF economic independence framework and shows its practical support of the small and medium knowledge-based enterprises.

There are two distinct parameters from the IKBF which can affect the financial target, the initial amount of the capital and the IKBF securities which are issued, providing the finance for the lending process operation. If the government, opens remittances at the national bank more than its credit, it will cause the budget deficit and debt increasing, once; but the deficit effect reaches to zero, after that ${ }^{[32]}$. Since the IKBF's dividends, consumed for the remittance refund, the debt level will be reduced. The IKBF no negative impact on budget deficit increasing, make the plan acceptable. In 2014 budget, 200 Million \$ was approved for the innovation and prosperity fund, protection, which is acceptable for beginning. But this lending process, doesn't have perfect transparency. In 2016, 1 billion $\$$ was agreed to dedicate the fund and a comprehensive plan for how to assign it, is under study. Calculation of principal and branches and the obligations, which IKBF issues the bonds based on them, is the bigger problem. With government ownership, the investment fund should be a part of general section; any financial commitments which bank accepts, has credit, same as its lending process, both as a public debt and public loan. Therefore, that debt which IKBF provides the knowledge-based projects capital via that, increases the public section deficit. If the BIB framework applied as the guide, IKBF can move along the profit, rapidly. Its loans, provided by its lending credits; the unique experiment that can be done in Iranian public financial funds, for the first time, it pays the dividends to the government and improves the employment and development simultaneously. Finally, the IKBF makes a powerful governmental-political sample, based on transparency and the true banking processes.

\section{Conclusion}

Knowledge-based products don't have fast profitability and they need a long time to conquer the market due to internal and innovative problems, intrinsic risks and target markets' novelty. Unsuitable space for the business in Iran, on the other hand, exacerbates this issue especially for the knowledge-based technologies. The market of potential knowledge-based plans, generally, is risky and unknown, because the appropriate result obtaining in these product market, usually need to time wasting and long term. Investing in knowledge-based industries are a long-term investment, due to their intrinsic risks as a result of their innovative plan. Therefore, the popular financial mechanisms are not proper for their assessment and financial providing. Banks, thus, don't have high interest for the investment in knowledge-based activities, due to existed risks. Consequently, the most appropriate investment device in knowledge-based plans is the logical-venturous investment. the IKBF framework can play an important role in Iran movement towards the financial transparency and protection of the small and medium scale knowledge-based enterprises. Finding a proper sketch and political unanimity about the behavior way and national calculations was the aim of present study. BIB suggestion framework with some modifications in relation with political stricter can be used in Iran.

\section{References}

[1] Kanani M, Goodarzi M. Fostering new technology-based firms in Iran: Inspiration of world models in solving domestic challenges. The development of science and technology in Iran. 2017; 29-43.

[2] Salamzadeh A, Kesim HK. The enterprising communities and startup ecosystem in Iran. Journal of Enterprising Communities: People and Places in the Global Economy. 2017; 11(4): 456-479.

[3] Ghazinoory S, Narimani M, Tatina S. Neoclassical versus evolutionary economics in developing countries: Convergence of policy implications. Journal of Evolutionary Economics. 2017; 27(3): 555-583. 
[4] Akbarzadeh N, Shafiezadeh E. A study on the role of government in improving the process of launch and development of knowledge-based businesses. Growth Technology. 2013; 9: 46-55.

[5] Gholipour M, Vahdatzad M, Owlia MS, Khademi ZH. Identification and priorities kbes challenges using ann method (case study: yazds kbes). Roshd-E-Fanavari. 2016; 12(45): 17-25.

[6] Fakhari H. Review of knowledge-based firms definition consistent with the economic conditions of iran. Journal Of Science And Technology Policy. 2015; 6(4): 69-88.

[7] Chaharband F, Momeni F. Challenges and perspectives in knowledge based development in Iran: Basic education approach. Journal of economic growth and development research. 2011; 1(4): 75-115.

[8] Bonoli G. Active labour market policy and social investment: a changing relationship. Towards a social investment welfare state. 2012; 181-204.

[9] Fritsch M, Kritikos A, Pijnenburg K. Business cycles, unemployment and entrepreneurial entry-evidence from Germany. International Entrepreneurship and Management Journal. 2015; 11(2): 267-286.

[10] ADB AA, Furceri D, IMF PT. The macroeconomic effects of public investment: Evidence from advanced economies. Journal of Macroeconomics. 2016; 50: 224-240.

[11] Soylu ÖB, Çakmak İ, Okur F. Economic growth and unemployment issue: Panel data analysis in Eastern European Countries. The Journal of international studies. 2018; 11(1): 93-107.

[12] Van Roy V, Vértesy D, Vivarelli M. Technology and employment: Mass unemployment or job creation? Empirical evidence from European patenting firms. Research Policy. 2018; 47(9):1762-1776.

[13] Dvouletý O. Can policy makers count with positive impact of entrepreneurship on economic development of the Czech regions? Journal of Entrepreneurship in Emerging Economies. 2017; 9(3): 286-299.

[14] Kilic M, Wachter JA. Risk, unemployment, and the stock market: A rare-event-based explanation of labor market volatility. The Review of Financial Studies. 2018; 31(12): 4762-4814.

[15] Rezaei Moghaddam K, Izadi H. Entrepreneurship in small agricultural quick-impact enterprises in Iran: development of an index, effective factors and obstacles. Journal of Global Entrepreneurship Research. 2019; 9(1): 17.

[16] Alinejad EA, Pishvaee MS, Naeini AB. Key success factors for logistics provider enterprises: an empirical investigation in Iran. Kybernetes. 2018; 47(3): 426-440.

[17] Afshar Jahanshahi A, Al Gamrh B, Gharleghi B. Sustainable development in Iran post-sanction: Embracing green innovation by small and medium-sized enterprises. Sustainable Development. 2020; 28(4): 781-790.

[18] Sadeghi A. Success factors of high-tech SMEs in Iran: A fuzzy MCDM approach. The Journal of High Technology Management Research. 2018; 29(1): 71-87.

[19] Salim A, Razavi MR, Afshari-Mofrad M. Foreign direct investment and technology spillover in Iran: The role of technological capabilities of subsidiaries. Technological Forecasting and Social Change. 2017; 122: 207-214.

[20] Harris L. Barriers to market orientation: The view from the shopfloor. Marketing Intelligence \& Planning. 1998; 16(3): 221-228.

[21] Cooray N. Cleaner production assessment in small and medium industries of Sri Lanka. Global Competitiveness through Cleaner Production: Second Asia Pacific Cleaner Production Roundtable. 1999.

[22] Porter ME. On Competition. Harvard Business Press; 2008.

[23] Wigstrom CW. A British Investment Bank: Why and How? Global Policy. 2013; 4(1): $22-29$.

[24] Dolphin T, Nash D. Investing for the future: Why we need a British Investment Bank. IPPR; 2012.

[25] Skidelsky R, Martin F, Wigstrom CW. Blueprint for a British Investment Bank. London: Centre for Global Studies; 2011.

[26] MEAF MoEAaF. The state of the country's labor market and its vision on the horizon of 14 April 2016. Available from: http://www.mefa.ir/portal/home/?86616/Reports.

[27] Islamic Parliament Research Center I. Unemployment in Iran between in end of 2020. 2014.

[28] Khamenei A. Leader meets government officials 2012. 2016. Available from: http://english.khamenei.ir/news/1654/ Leader-Meets-Government-Officials.

[29] Khamenei A. Leader's address to people active in economic sector 2011. Available from: http://english.khamenei.ir/ news/1508/Leader-s-Address-to-People-Active-in-Economic-Sector.

[30] Khamenei A. Leader meets with entrepreneurs 2010. Available from: http://english.khamenei.ir/news/1343/Leader-Meets-with-Entrepreneurs.

[31] Khamenei A. Leader announces general policies of fifth development plan. 2009. Available from: https://english. khamenei.ir/news/1027/Leader-Announces-General-Policies-of-Fifth-Development-Plan.

[32] Skidelsky R, Martin F. For a national investment bank. Learning from the World. Springer; 2014. p.106-113. 